Return to the Manage Active Submissions page at http://spie.org/submissions/tasks.aspx and approve or disapprove this submission. Your manuscript will not be published without this approval. Please contact author_help@spie.org with any questions or concerns.

\title{
Urban remote sensing in areas of conflict: TerraSAR-X and Sentinel-1 change detection in the Middle East
}

\author{
Deodato Tapete*a, Francesca Cigna ${ }^{\mathrm{a}}$ \\ ${ }^{a}$ British Geological Survey (BGS), Natural Environment Research Council (NERC), \\ Nicker Hill, NG12 5GG Keyworth, United Kingdom
}

\begin{abstract}
Timely availability of images of suitable spatial resolution, temporal frequency and coverage is currently one of the major technical constraints on the application of satellite SAR remote sensing for the conservation of heritage assets in urban environments that are impacted by human-induced transformation. TerraSAR-X and Sentinel-1A, in this regard, are two different models of SAR data provision: very high resolution on-demand imagery with end user-selected acquisition parameters, on one side, and freely accessible GIS-ready products with intended regular temporal coverage, on the other. What this means for change detection analyses in urban areas is demonstrated in this paper via the experiment over Homs, the third largest city of Syria with an history of settlement since $2300 \mathrm{BCE}$, where the impacts of the recent civil war combine with pre- and post-conflict urban transformation. The potential performance of Sentinel-1A StripMap scenes acquired in an emergency context is simulated via the matching StripMap beam mode offered by TerraSAR-X. Benefits and limitations of the different radar frequency band, spatial resolution and single/multi-channel polarization are discussed, as a proof-of-concept of regular monitoring currently achievable with space-borne SAR in historic urban settings. Urban transformation observed across Homs in 2009, 2014 and 2015 shows the impact of the Syrian conflict on the cityscape and proves that operator-driven interpretation is required to understand the complexity of multiple and overlapping urban changes.
\end{abstract}

Keywords: Synthetic Aperture Radar, SAR backscatter, Sentinel-1, TerraSAR-X, change detection, cultural heritage, Syria

\section{INTRODUCTION}

The Hague Convention adopted by UNESCO in 1954 [1] acknowledges the risk of destruction of heritage assets and features of cultural value in the event of armed conflict. In cities with centuries or millennia of history, this threat can manifest in a variety of forms including the loss of historical buildings, the modification of cityscape landmarks and, in some cases, alteration of the city form and urban layout [2].

Systematic appraisal of changes and damage based on field surveys is frequently unfeasible during conflict for the safety of the operators and, anyway, not necessarily the best way to retrieve a holistic view across the full extent of a city. Remote sensing from space, therefore, is regarded as a source of objective information over heritage sites with restricted access [3,4]. While optical images and aerial photographs are still the most common Earth Observation solutions exploited, Synthetic Aperture Radar (SAR) imagery is increasingly used for quantitative assessment, also as a consequence of the improved spatial resolution $[5,6]$.

Visibility along the line of sight of the satellite being equal, spatial resolution is indeed one of the essential technical requirements to achieve an effective discrimination within densely built-up areas and complex urban environments. This seems to be even more applicable in contexts of armed conflict when the observed changes in the cityscape might not follow predictable models or usual spatial patterns. While the highest resolution is always desirable and advantageous, experience demonstrates that it is best to have images of resolution and spatial coverage suitable enough to the scale and extent of the changes to detect, acquired and provided timely to compare the situation prior to, during and after the emergency.

It is against these factors and operational needs that this paper aims to evaluate current C-and X-band SAR missions.

*deodato@bgs.ac.uk; phone +44115936 3537; fax +441159363446

RS100 - 57 V. 1 (p.1 of 7) / Color: No / Format: A4 / Date: 3/28/2016 5:59:40 PM

SPIE USE: DB Check, Prod Check, Notes: 
Return to the Manage Active Submissions page at http://spie.org/submissions/tasks.aspx and approve or disapprove this submission. Your manuscript will not be published without this approval. Please contact author_help@spie.org with any questions or concerns.

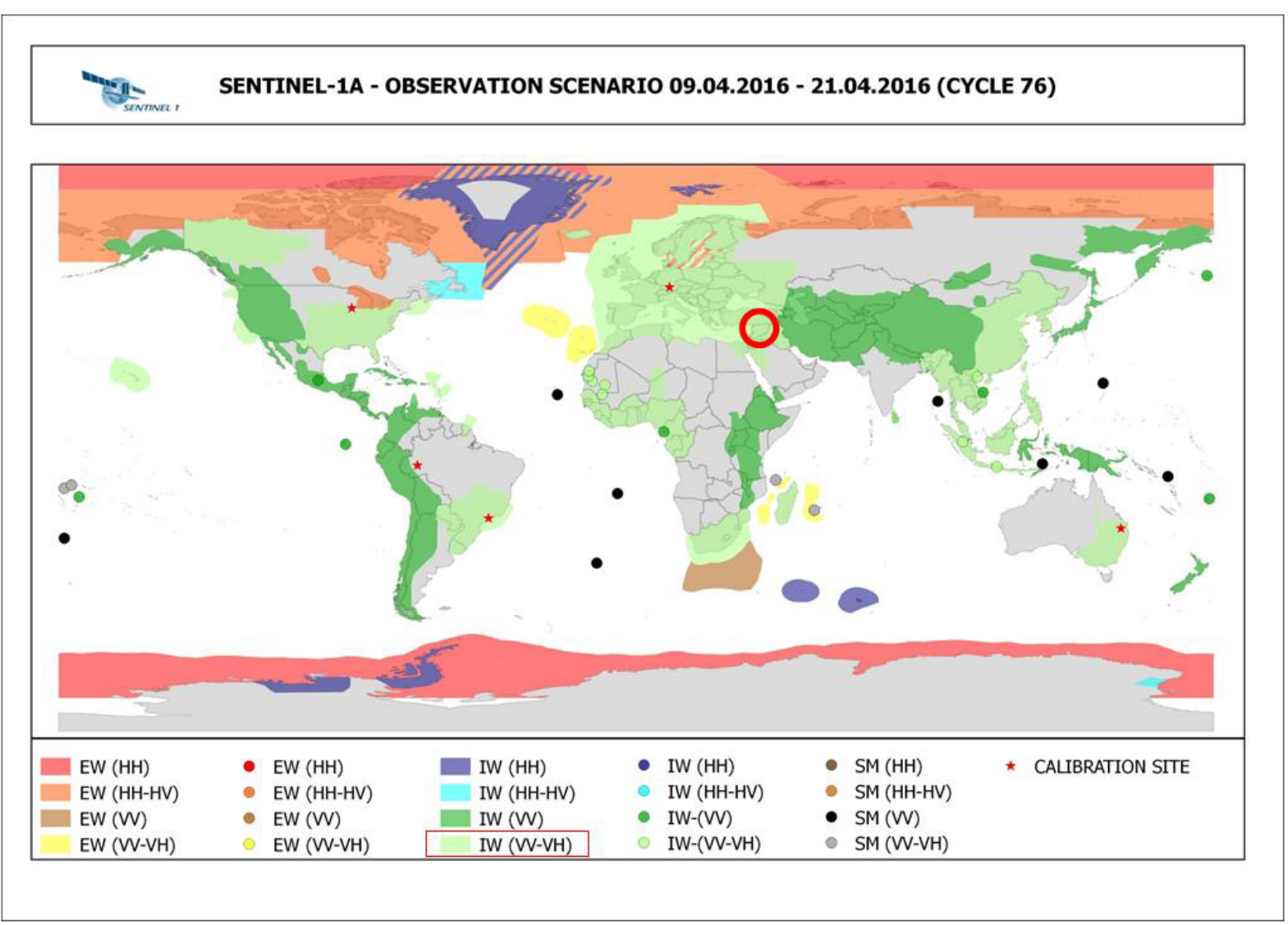

Figure 1. Observation Scenario of Sentinel-1A in April 2016. Dual pol Interferometric Wide Swath (IW) is scheduled as pre-defined acquisition mode over Syria (red circle). Figure modified from [7].

\section{MATERIALS AND METHODS}

The European Space Agency (ESA) Sentinel-1A (S1A) satellite and the German Aerospace Center (DLR) TerraSAR-X (TSX) constellation are exemplars of two different models of SAR data provision: freely accessible GIS-ready products with intended regular temporal coverage, on one side; very high resolution on-demand imagery with end user-selected acquisition parameters, on the other.

Acquiring images of the Earth's surface since October 2014, S1A follows a baseline pre-defined mission observation scenario [7]. Over Europe, North Africa and Middle East - the latter of concern for this study - the scenario foresees regular acquisition of Interferometric Wide Swath (IW), dual pol (VV-VH polarization), $250 \mathrm{~km}$ swath and $5 \times 20 \mathrm{~m}$ spatial resolution, every 12 days of repeat cycle per pass (Figure 1). In exceptional cases only, emergency observation requests may alter the pre-defined observation scenario, possibly requiring use of the StripMap (SM) mode, i.e. $80 \mathrm{~km}$ swath, 5 × $5 \mathrm{~m}$ spatial resolution [8].

The current S1A archive accessible from the Sentinel Scientific Data Hub [9] confirms this scenario over the region of Homs, western Syria (Figure 2; section 3), with already hundreds of IW products, but none acquired in SM mode. IW VV products acquired on 06/10/2014, 05/12/2014 and 21/02/2015 were analysed for the purposes of this research and an RGB colour composite was generated (see section 3.2) according to the methodology of change detection by Tapete et al. [10]. 
Return to the Manage Active Submissions page at http://spie.org/submissions/tasks.aspx and approve or disapprove this submission. Your manuscript will not be published without this approval. Please contact author_help@spie.org with any questions or concerns.
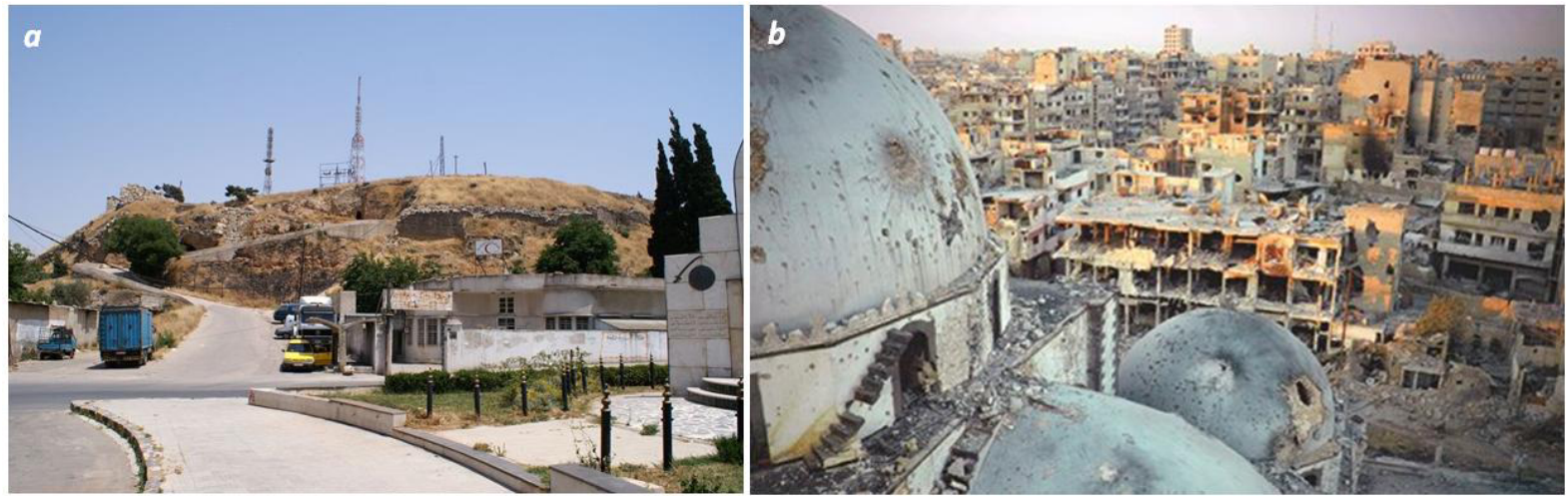

Figure 2. (a) Bottom view of the Citadel of Homs (also known as 'Tell Homs') in 2006 before the Syrian civil war (from Panoramio [11] (c) Peter van der Wielen All rights reserved); (b) domes of Khalid ibn al-Walid Mosque, north Homs, and the surrounding residential quarter heavily damaged during shelling in 2013.

To demonstrate what S1A and, in the future, the full S1 constellation might provide on an emergency basis if SM images are acquired, we present the results of a multi-temporal analysis using a bespoke time series of 3-metre resolution TerraSAR-X SM scenes with VV polarization, acquired along ascending orbits. These images were accessed in the framework of the TSX-New-Modes-2013 LAN2377 project with DLR, to analyse the urban scenario of Homs city as recorded on 17/08/2009, 05/12/2014 and 30/05/2015. Amplitude change detection was undertaken according to Cigna et al. [12].

\section{EXPERIMENTAL RESULTS IN HOMS, SYRIA}

\subsection{Test site}

Homs, western Syria (coordinates LAT $34.72^{\circ}$; LON $36.71^{\circ}$ ), was the third largest city of the country before the Syrian civil war started in March 2011. The city has a long history of occupation, with archaeological evidence of the earliest settlement found in the Citadel of Homs (Figure 2a) dating back to around 2300 BCE [13]. The Citadel is the most noticeable landscape landmark of the cityscape, as it is built at the top of a prominent Early Bronze Age 'tell' is situated in the centre of Homs. Structures of the former walls built during the the Ayyubid period can still be seen along the slopes, while in modern times antennas were installed to exploit the tell elevation (about $526 \mathrm{~m}$ ) for signal transmission.

During the recent civil war, Homs was an opposition stronghold to the central government and was heavily shelled since May 2011. Several buildings and heritage assets were severely damaged, such as the Khalid ibn al-Walid Mosque built $1.5 \mathrm{~km}$ north of the Citadel of Homs during the Turkish Ottoman period (Figure 2b). The western quarter of Bab Amr is among the residential areas of the city that were particularly impacted by the fighting and bombing. Satellite image analysis by Human Rights Watch on 25 February 2012 highlighted the extent of the damage in Bab Amr with at least 950 craters visible on open land [14], while drone footage recently distributed across the international media provides a close view to understand the scale of devastation of the urban fabric [15].

\subsection{Sentinel-1A analysis}

Figure 3 shows an example of the RGB colour composites generated from S1A archive data. The IW mode swath of 250 $\mathrm{km}$ allows a simultaneous coverage of the whole extent of Homs, thereby providing a comprehensive picture of the urban setting and surrounding rural areas. Spatial patterns due to changes caused by anthropogenic actions (Figure 3a) and natural processes (Figure $3 \mathrm{~b}$ ) are recognized, although the latter are more easily detectable as they occurred in open land and were not hidden by the dense urban fabric. For instance, local inundation from the River Orontes affected agricultural fields and floodplain in proximity of Al-Wair quarter in the period December 2014 - January 2015 (Figure $3 \mathrm{~b}$ ), confirming the susceptibility of this area to fluvial flooding. 
Return to the Manage Active Submissions page at http://spie.org/submissions/tasks.aspx and approve or disapprove this submission. Your manuscript will not be published without this approval. Please contact author_help@spie.org with any questions or concerns.

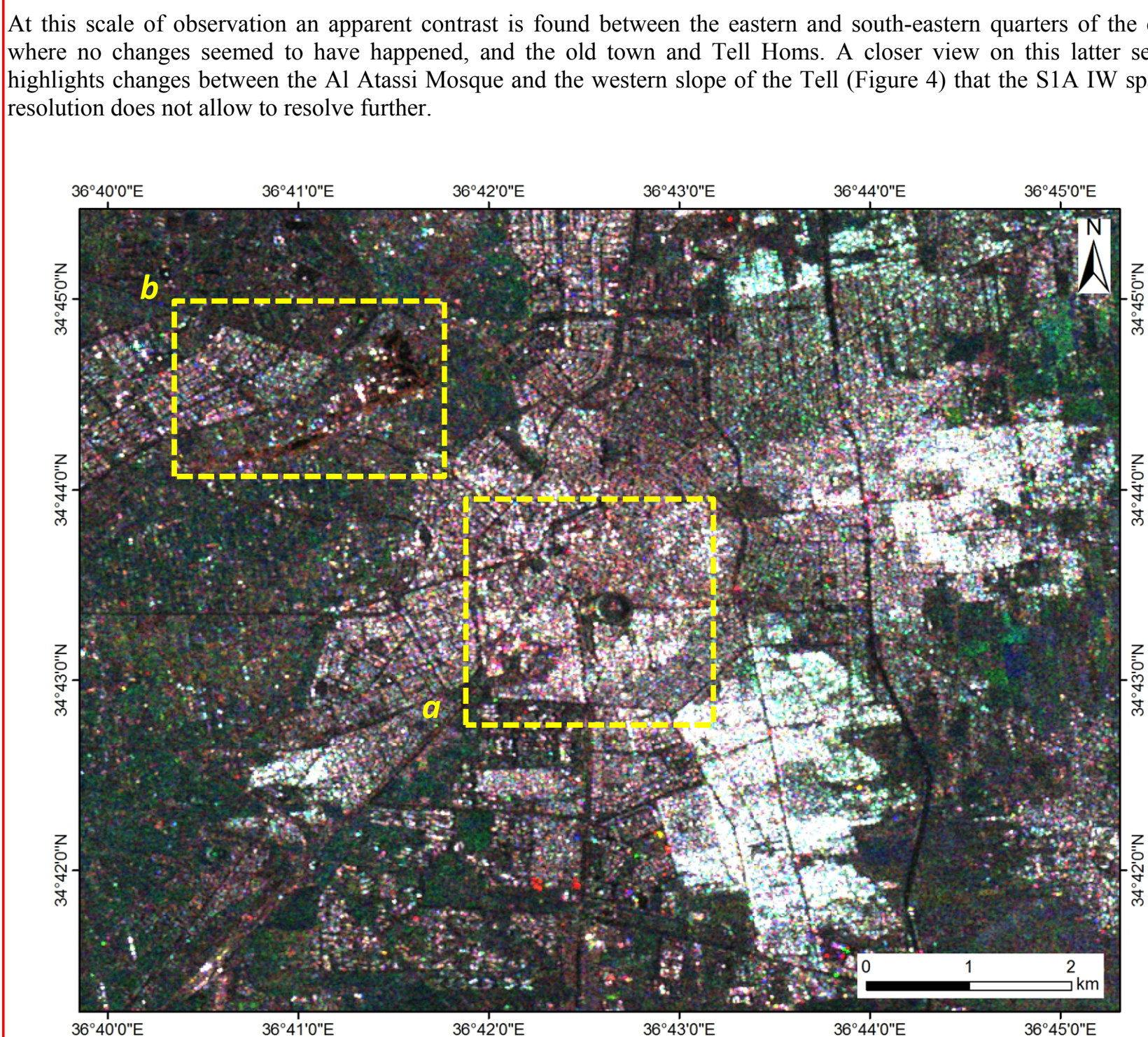

Figure 3. RGB colour composite over the city of Homs, generated from S1A IW VV ascending time series with channels: Red - October 2014; Green - December 2014; Blue - February 2015. (a) Citadel of Homs and old town; (b) River Orontes flowing close to Al-Wair quarter, with evidence of winter flooding. S1A data C ESA 2015. 
Return to the Manage Active Submissions page at http://spie.org/submissions/tasks.aspx and approve or disapprove this submission. Your manuscript will not be published without this approval. Please contact author_help@spie.org with any questions or concerns.

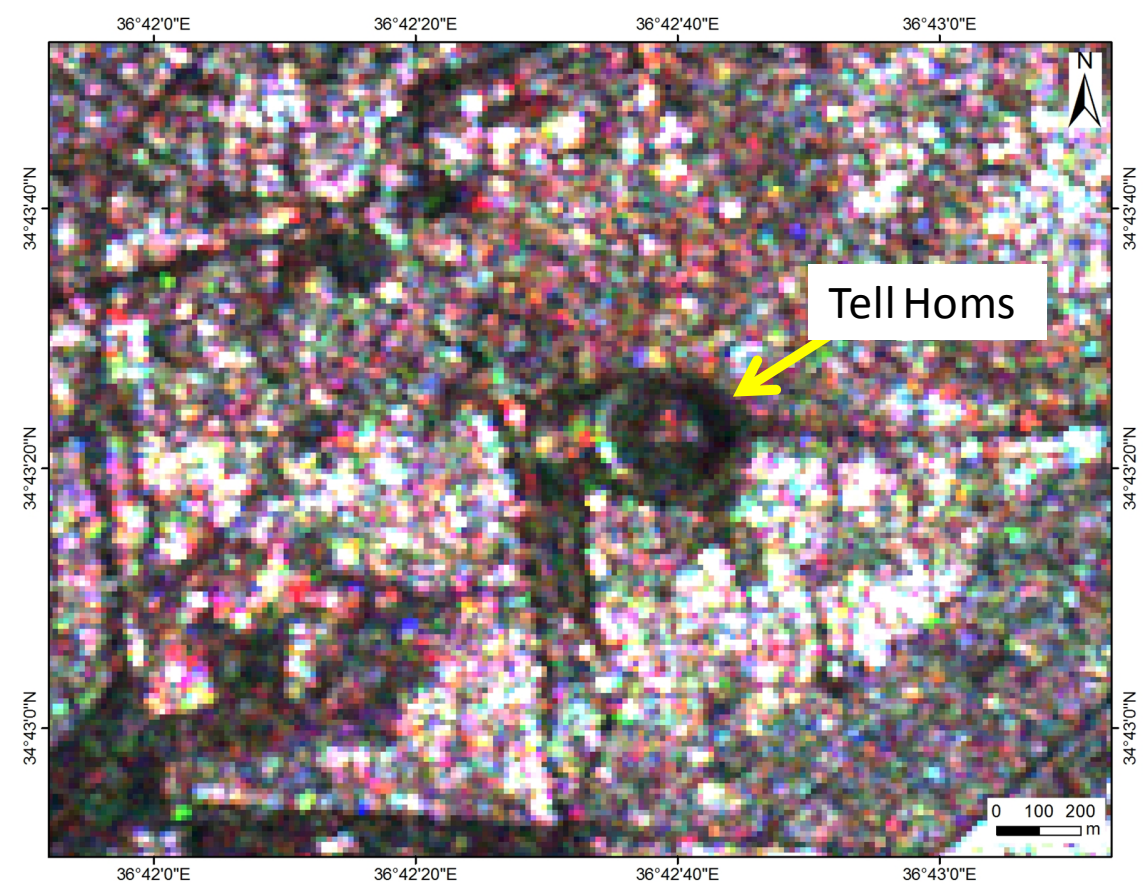

Figure 4. Zoomed view of the S1A IW RGB colour composite in the area of Tell Homs (see location in Figure 3a). Changes are observed between the Al Atassi Mosque and the western slope of the Tell. S1A data (C) ESA 2015.

\subsection{TerraSAR-X analysis}

Figure 5a shows the amplitude change detection map based upon the comparison of a pair of 3-m resolution VV SM TSX acquisitions acquired along orbit 39 and ascending passes in August 2009, i.e. prior to the civil war, and December 2014, i.e. after the major impact of shelling. It is worth noting that the latter TSX scene was acquired on the same day as the second S1A IW image.

The improved spatial resolution of TSX SM data allows a more precise delineation of the pattern associated with the radar backscatter change on the road pavement between the Al Atassi Mosque and the western slope of Tell Homs (Figure 5a-b, f). In particular, the cyan colour in the RC composite suggests the presence of objects with strong radar backscatter in December 2014 (Figure 5f). A comparison with the time series of Google Earth imagery confirms that the observed pattern was due to a military blockage built with earthen materials, likely quarried from the Tell slope (Figure $5 \mathrm{~g}$ ). No patterns of damage are apparent over the Al Atassi Mosque based on the TSX data.

Trenches, excavations and embankments built for defensive purposes are found sparsely across the cityscape. Box (c) in Figure 5a marks some of these features in the open land located west of the Homs University estates.

Given the wide temporal window between the two TSX acquisitions, our analysis spots other changes across the city that do not relate to war damage. An example is found in a residential area in the north (see box (d) in Figure 5a) where buildings were demolished before the war. Similarly, the red pattern along the River Orontes in proximity to Al-Wair quarter (Figure 5e) is due to fluvial flooding and matches with the pattern found in the S1A IW RGB colour composite (Figure 3b). 
Return to the Manage Active Submissions page at http://spie.org/submissions/tasks.aspx and approve or disapprove this submission. Your manuscript will not be published without this approval. Please contact author_help@spie.org with any questions or concerns.
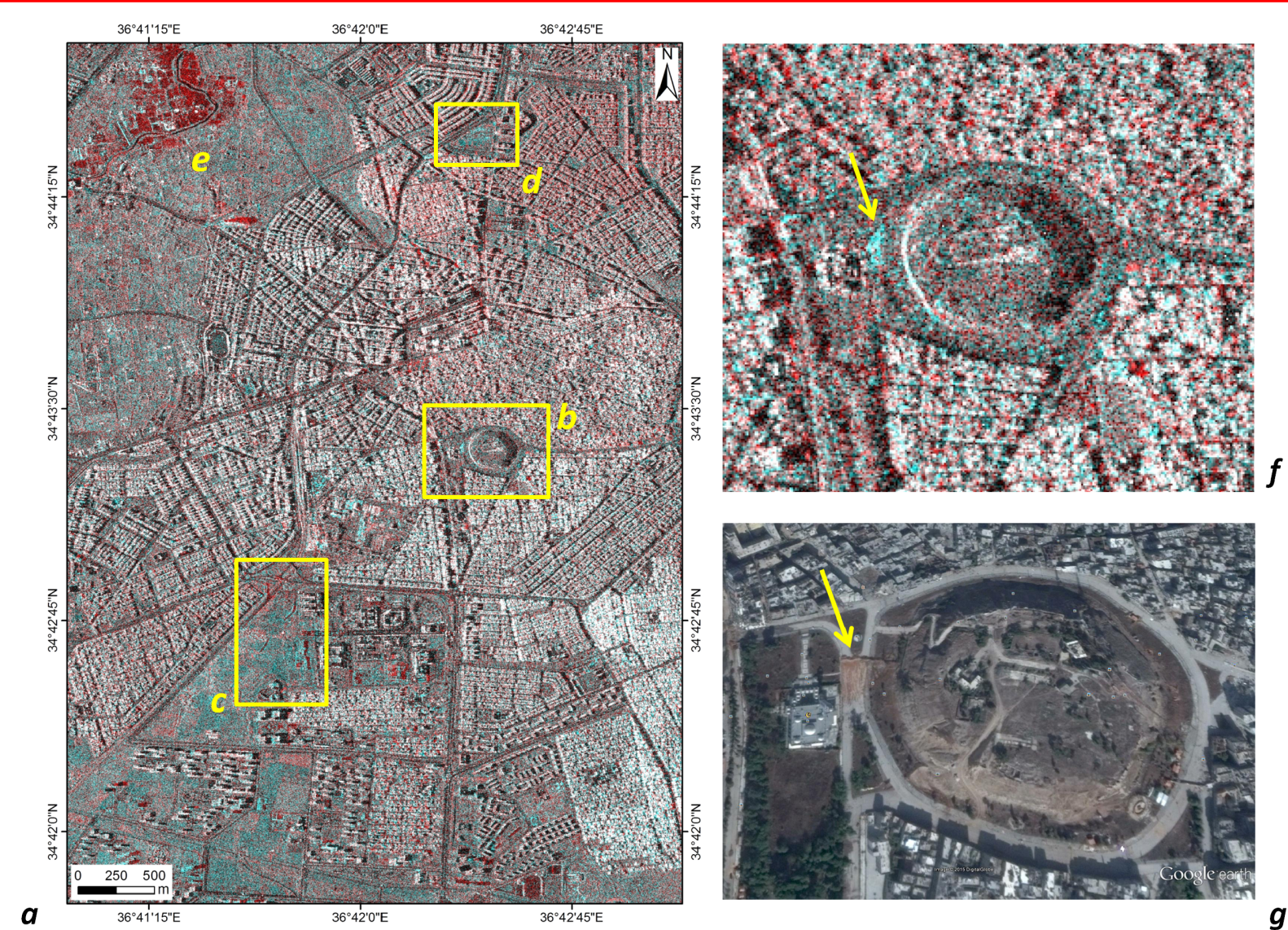

Figure 5. (a) RC color composite of 17/08/2009 and 05/12/2014 VV SM TSX over Homs, Syria (C) DLR 2014-2015), with examples of damages and changes in the urban setting: (b) military blockage at the foot of Tell Homs; (b) trenches and embankments in the area of Homs University; (c) area of pre-war building demolition, northern quarter of Homs; (d) flooding from the River Orontes (see also Figure 3b). (f) Zoom over Tell Homs and matching (e) Google Earth image acquired on 31/10/2013 (Image (C2016 DigitalGlobe) showing the extent of the earthen blockage.

\section{DISCUSSION AND CONCLUSIONS}

The trials of change detection analysis based on regular S1A IW acquisitions and the simulation, via TSX SM time series, of the operational capability of S1A operating in SM mode during emergencies demonstrate that SAR can be a valuable and viable solution for urban remote sensing in context of armed conflict, if timely acquisitions are available and the spatial coverage and resolution are commensurate with the size and temporal frequency of the events to detect.

Over Homs, S1A and TSX proved complementary Earth Observation solutions to retrieve a clear picture of the urban dynamics occurred prior to and after the civil war, and to observe the appearance of new features across the cityscape that directly or indirectly relate to the recent conflict.

There might be a question whether SAR should be used instead of optical imagery to map urban dynamics, as the latter are generally easier to interpret and preferred by a wide range of image analysts. In this regard, the operability under any weather conditions, GIS-readiness of pre-processed image products, regularity of acquisition and accessibility at no costs to archive imagery are key factors that should encourage the exploitation of SAR for such applications. Spatial resolution can still represent a constraint, particularly for S1A, as the current pre-defined acquisition mode and baseline observation scenario seem not to provide images of sufficient resolution to undertake local scale assessments. 
Return to the Manage Active Submissions page at http://spie.org/submissions/tasks.aspx and approve or disapprove this submission. Your manuscript will not be published without this approval. Please contact author_help@spie.org with any questions or concerns.

Interpretation-wise, whilst processing automation and implementation of change detection routines are undoubtedly beneficial towards a highly responsive analysis in situation of armed conflict, the operator's judgment on observed spatial patterns and integration with other Earth Observation data or sources of information are still necessary. The examples of pre-war building demolitions and fluvial flooding discussed in section 3 demonstrate the risk of misinterpretation due to a blind approach of pattern analysis.

\section{ACKNOWLEDGEMENTS}

This research was led by Dr D. Tapete, supported by a European Union COFUND/Durham Junior Research Fellowship [under EU grant agreement no. 267209]. Sentinel-1A data were accessed via the European Space Agency's Sentinel Scientific Data Hub. TerraSAR-X and TanDEM-X data were sourced from DLR via the TSX-New-Modes-2013 LAN2377 (Principal Investigator: Dr D. Tapete) and processed using the GAMMA SAR and Interferometry Software licensed to BGS, NERC.

\section{REFERENCES}

[1] UNESCO, "Hague Convention, Convention for the Protection of Cultural Property in the Event of Armed Conflict, Adopted at The Hague", 14 May 1954, accessed on 28 March 2016, http://www.unesco.org/new/en/culture/themes/armed-conflict-and-heritage/the-hague-convention/text-of-theconvention-and-its-1st-protocol/\#c284179 (1954).

[2] Closmann, C. and Mauch, C. "War and the Environment: Contexts and consequences of Military Destruction in the Modern Age," GHI Bulletin 35 (Fall 2004), 167-171 (2004).

[3] United Nations Institute for Training and Research (UNITAR), "Satellite-based damage assessment to cultural heritage sites in Syria," UNITAR/UNOSAT, 93 pp. (2014).

[4] Cunliffe, E., "Satellites and Site Destruction: An Analysis of Modern Impacts on the Archaeological Resource of the Ancient Near East," Durham University (2013).

[5] Tapete, D., Cigna, F., Donoghue, D. N. M. and Philip, G., "Mapping changes and damages in areas of conflict: from archive C-band SAR data to new HR X-band imagery, towards the Sentinels," Proceedings of FRINGE workshop 2015, European Space Agency special publication ESA SP-731, European Space Agency, European Space Agency, Rome, Italy. 4 pp., doi: 10.5270/Fringe2015.149 (2015).

[6] Tapete, D., Cigna, F. and Donoghue, D. N. M., “'Looting marks' in space-borne SAR imagery: Measuring rates of archaeological looting in Apamea (Syria) with TerraSAR-X Staring Spotlight," Remote Sensing of Environment 178, 42-58 (2016).

[7] European Space Agency (ESA), "Sentinel-1 Observation Scenario", accessed on 28 March 2016, https://sentinel.esa.int/web/sentinel/missions/sentinel-1/observation-scenario (2016).

[8] Sentinel-1 Team, "Sentinel-1 User Handbook. GMES-S1OP-EOPG-TN-13-0001," 80 pp. (2013).

[9] European Space Agency (ESA), "Sentinels Scientific Data Hub", accessed on 28 March 2016. https://scihub.copernicus.eu/ (2016).

[10] Tapete, D., Cigna, F., Masini, N. and Lasaponara, R. "Prospection and monitoring of the archaeological heritage of Nasca, Peru, with ENVISAT ASAR," Archaeological Prospection 20, 133-147 (2013).

[11] Panoramio, "Homs, site of the citadel. Photo 02/06/2006 by Peter van der Wielen", accessed on 28 March 2016, http://www.panoramio.com/photo/2290479 (2006).

[12] Cigna, F., Tapete, D., Lasaponara, R. and Masini, N. "Amplitude change detection with ENVISAT ASAR to image the cultural landscape of the Nasca Region, Peru," Archaeological Prospection 20, 117-131 (2013).

[13] King, G. R. D. "Archaeological fieldwork at the Citadel of Homs, Syria: 1995-1999 = Chantier archéologique de la Citadelle d'Homs, Syrie: 1995-1999" Levant 34, 39-58 (2002).

[14] Human Rights Watch, "Syria: New Satellite Images Show Homs Shelling", 2 March 2012, accessed on 28 March 2016, https://www.hrw.org/news/2012/03/02/syria-new-satellite-images-show-homs-shelling (2012).

[15] RussiaWorks, "Drone footage of Homs in Syria shows utter devastation - video", 4 February 2016, accessed on 28 March 2016, http://www.theguardian.com/world/video/2016/feb/04/drone-footage-homs-syria-utterdevastation-video (2016). 